\title{
THE PASSION TO TEACH: A DIALOGUE WITH BRIAN P. COPPOLA
}

\author{
Liberato Cardellini \\ Marche Polytechnic University, Ancona, Italy \\ I.cardellini@univpm.it
}

\section{A Brief Biographical Sketch}

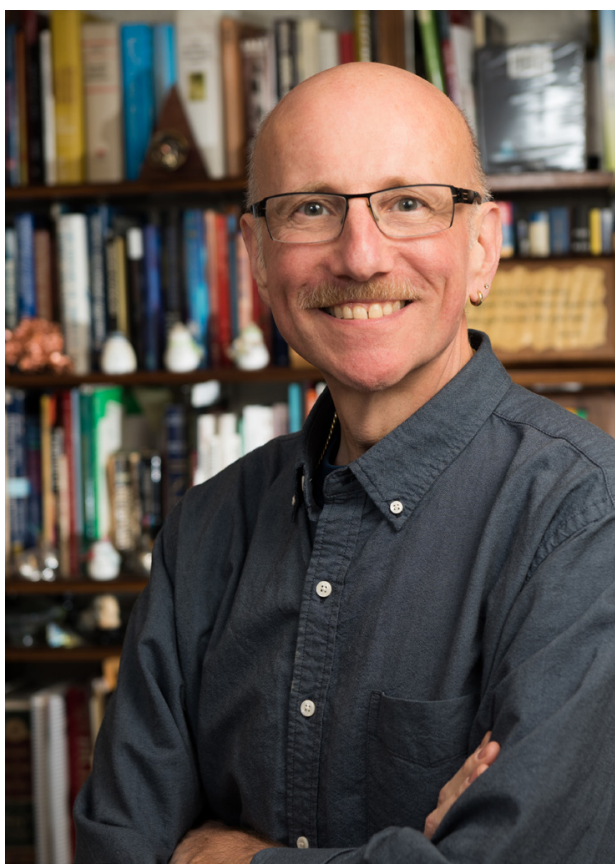

Dr. Brian P. Coppola is Arthur F. Thurnau Professor of Chemistry at the University of Michigan. He was born in 1957, the same year that Sputnik launched, and was educated by many of the progressive school science movements of the 1960s. He excelled in the college preparatory program at Pinkerton Academy, in Derry, $\mathrm{NH}$. He received his B.S. d egree in Chemistry in 1978 from the University of New Hampshire, where he also pursued his interest in art, particularly drawing. In 1980, during graduate school at the University of Wisconsin-Madison, while volunteering as the first study group leader in organic chemistry for the Greater University Tutorial Service (GUTS), Coppola had a chance encounter with Harry Behrman. Behrman invented the GUTS program as a part of his $\mathrm{PhD}$ in Education, and he ended up sitting in the back of Coppola's study group room, taking field notes for his thesis. Every week, Behrman and Coppola had a few hours of intense conversation about education as a field of scholarly endeavor, the integration of which into science formed the foundation of Coppola's professional interests and future plans.

Coppola earned his Ph.D. in Organic Chemistry from the University of WisconsinMadison in 1984, having already served for two years as a lecturer at the University of Wisconsin-Whitewater. Moving to Ann Arbor in 1986, as a lecturer, he joined an active group of faculty in the design and implementation of a revised undergraduate chemistry curriculum. His 1996-7 tenure review established a new policy within the College of Literature, Science and Arts at the University of Michigan, recognizing discipline-centered teaching and learning as an area that can be represented within the LSA departments (Huber, 2004). He was promoted to Full Professor of Chemistry in 2001-2. 
From 2002-12, Coppola served as the department's fifth Associate Chair for Curriculum and Faculty Affairs, and in 2012 he was appointed as the first Associate Chair for Educational Development and Practice. In this capacity, he is primarily responsible for directing of the department's future faculty program, in which undergraduate students, graduate students, and post-doctoral associates work with faculty members on teaching and learning projects within the department.

Working with a group of undergraduate research students, Coppola published a few noteworthy studies that contributed to understanding the influence of non-covalent interactions on the regioselectivity of 1,3-dipolar cycloaddition reactions of mesoionic münchnones (Coppola et al., 1993; Coppola, Noe \& Hong, 1997). The centrality and power of the discipline plays a consistent role in Coppola's work (Coppola \& Krajcik, 2013). He has promoted the advantages of collaboration with colleagues in psychology, educational psychology, education, and the learning sciences, where the sum of expertise is greater than what an individual might bring to work in teaching and learning (Zusho et al., 2003; Coppola, 2013). Since he moved to Ann Arbor, the undergraduate organic chemistry program at the University of Michigan has featured a steady connection between the original literature, authentic learning, and research-based instructional design (Coppola \& Lawton, 1995; Ege et al., 1997; Coppola et al., 1997; Gottfried et al., 2007).

Combining his experience with the GUTS program, as a graduate student, with his experience in art classes, as an undergraduate, Coppola and his student collaborators launched the Structured Study Group program in 1994, a peer-led, team-based supplemental instruction program that features studio-inspired assignments using the original literature, student-generated instructional materials, as well as proposing, planning, and carrying out modestly scaled research projects.

Coppola was an early contributor to the Carnegie Foundation's efforts to define and develop the Scholarship of Teaching and Learning. His interest starts with understanding how scholarship in discovery science is developed through the special intergenerational communities we call "research groups." As a technology, this strategy can be broadened to provide "teaching groups" as a way for any mainstream faculty member to pursue scholarship in teaching and learning. Future faculty education plays the key role in this plan. New faculty members, Coppola contends, should be as prepared to carry out their independent responsibilities for education as they are for carrying out their independent research careers (Coppola, 2007, p. 1905):

If scholarship not only includes the objects of and processes for carrying out scholarly work (informed, intentional, impermanent), but also pays explicit attention to how we educate the next generation (inheritable), then an approach where all of these pieces are staked out and allowed to grow together might be necessary.

Coppola's new appointment in his department is associated with the establishment of budgeted positions for all members of the intergenerational community, from undergraduate students to postdoctoral associates, who wish to collaborate with faculty members on instructional development and/or assessment. This program provides a mechanism for energizing the consistent attention to teaching, in the department, that parallels its research activity. 
He is an Associate Editor for The Journal for Research in Science Teaching, and the co-editor, along with Joseph Krajcik, of two special issues of JRST featuring disciplinecentered postsecondary science education research. Since 1998, he has been the editor in chief of The Hexagon, the quarterly publication of Alpha Chi Sigma, the professional chemistry fraternity. To his credit, he recognized the potential of a photograph, published in Scientific American, showing a chef making instant ice cream with liquid nitrogen. His short report in this Journal is the original source for this now-ubiquitous chemistry activity (Coppola et al., 1994); patent searches for the commercial deep-freeze processes always track the citation back to this paper. Looking back a little further, his first publications in this Journal, as an undergraduate, were a series of cartoons published in under the title Animated Alchemy (Jones \& Coppola, 1978), a habit that has also continued (Hoffmann et al., 2008).

From designing multi-faceted learning environments to educational research, everything in Brian Coppola's repertoire derives first and foremost from his internationally recognized excellence as a classroom instructor. A couple of generations of students, mostly interacting in large classroom settings (Coppola, 2002), have walked away with the lessons learned from a moral principle he calls "full human presence." (Coppola, 2001) In 1994, Coppola received the 4th campus-wide "Golden Apple Award" for outstanding teaching, a recognition organized and administered solely by undergraduate students. In 1996, he was awarded a United States Department of Energy, Undergraduate Computational Science Education Award. In 1998, Coppola was selected as part of the first group of Carnegie Scholars affiliated with The Carnegie Foundation for the Advancement of Teaching's CASTL program (Carnegie Academy on the Scholarship of Teaching and Learning). Coppola received the Amoco Foundation Award for Excellence in Undergraduate Teaching (1999), the Kendall-Hunt Outstanding Undergraduate Science Teacher Award from the Society for College Science Teachers (2003), American Chemical Society's James Flack Norris Award (2006). In 2002, he was elected as a Fellow of the American Association for the Advancement of Science. Coppola was named the State of Michigan Professor of the Year in the CASE/Carnegie US Professor of the Year program (2004), and in 2009 he was selected as the National CASE/Carnegie US Professor of the Year (for doctoral institutions). In 2012, he received the Robert Foster Cherry Award for Great Teaching.

In 1998, upon reflecting on the purpose and value of face-to-face interaction in classroom settings, Richard Zare urged the education principle of "Inspiration is more important than information." (Coppola, 1998). Even then, before this new and wrong-minded era of reducing an education to counting and reporting correct answers on standardized examinations and problem inventories, Zare was appealing to the core values for what really inspires learning: the unique talent of highly knowledgeable individuals who can summon the thunder, captivating, persuading, and motivating a crowd to learn. The awards listed here share the common thread of recognizing the uncommon qualities of a great teacher of chemistry, able to teach and to inspire learning. We are abandoning this human element, a chance for spontaneity lost in the dark beneath the glare of computer-projected slides. What we may need is a return to core values, and increasing need for professional skills and (full) human resources to engage and motivate students to study chemistry.

While my interview with Professor Coppola does not reveal any 'right formula' for transforming students in class, it may cause you to disrupt and question assumptions and beliefs that you have about education. Agree or disagree, I am absolutely sure it does not 
matter to the Professor, because it will hopefully inspire Journal readers to think again about having the greatest impact in their privileged role of educating, and not just informing, their students.

\section{The interview}

\section{Let's start with a brief biography: How would you describe your early education? Why did you choose to study chemistry, and to become a teacher?}

I had a love affair with education from the beginning. I started first grade at 5 years old, and I have two keen memories of that. On the first day of school, I recall the trauma of watching the parents all lined up along the far wall and abandoning this room full of children. This was upsetting and I cried about it. On the second day of first grade, I was still crying, but this was because I wanted to stay at school. The school called my parents to come drag me home at the end of that second day. I wanted to stay. I cannot recall not wanting to be a teacher. I was a good student, and I had some wonderful instructors. I idolized and emulated teachers. At some point during the fifth or sixth grade, I stopped going outside for break periods and started staying inside, tutoring and/or simply working with my peers on our lessons. I have been standing at the board, working with students, longer than I have been doing anything else.

My interest in science started in the sixth grade, thanks to Mrs. Marie Smith. I tracked her down in 2009 and learned her story. She majored in biology at San Francisco State College and never intended to be a teacher. Her husband, who was in the military, was stationed in New Hampshire. She grabbed a couple of summer certification classes at the University of New Hampshire, and took a job teaching science. By her own admission, she had no idea what she was doing, so she relied on her understanding of science. This is an important idea. Instead of rows of desks, Mrs. Smith's science class was a series of stations set out around the room, each with something to investigate. The one I recall was a cup full of washers, some string and a stopwatch, where I worked out the relationships about pendular motion. That was the only year Marie Smith ever taught at the pre-college level. Her husband was transferred back to California, and she went on for advanced degrees in biology, taught at the community college level, and after serving twice as a Dean, retired as a Vice Chancellor.

I am not $100 \%$ sure where my interest in chemistry came from. I think part of it is my contrary nature (no one likes this, so I am going to), and part of it was the freshman science program in high school: 1970-71. We used the National Science Foundation's "Introductory Physical Science" (IPS) program, which was launched in 1967 as one of many post-Sputnik science reforms. What I recall of those many IPS experiments and demonstrations are all related to chemistry: distilling a wooden splint for methanol, collecting hydrogen gas from combining zinc turnings with acid, and the classroom demo of temperature/pressure relationships using some sort of large piston and a bouncing diaphragm of ball bearings.

I graduated from Pinkerton Academy with the prize for achievement in chemistry, and I entered the University of New Hampshire, as a chemistry major, in 1974. I loved organic chemistry, and I had a terrific professor: Robert E. Lyle. Bob was another in a long string of dedicated educators who knew that an important part of the job of being a good 
teacher is identifying and nurturing the next generation. He invited me into his research group (my reaction: "really ... can I do that?"). Bob moved to Texas, and I finished up with the new hire, Gary R. Weisman. Both Bob and Gary were graduates of UW-Madison, so it is perhaps not so shocking that I ended up there.

I worked with Barry M. Trost for my PhD, and Barry's eye was squarely centered on his students' educations. You see these things in retrospect a lot more clearly than the time, for sure. But I repeat often the story of what he said in 2001, at the symposium organized for his $60^{\text {th }}$ birthday (paraphrasing): my colleagues confuse me with their perpetual insistence that research productivity is the first and foremost outcome from academic science. When I look around the room, what I see is the real outcome: educating people and getting them out into the world. After all, if research productivity was, in fact, the primary outcome, why do we spend all of this time doing it with untrained scientists? I think this is such a marvelous way to make the point.

During graduate school, I volunteered my teaching services to a new organization on the Madison campus called GUTS (Greater University Tutorial Service). At the time, GUTS was the graduate project of some students in the School of Education, and they were running this as a student organization out of the Union. Every week, I was leading a discussion group made up of 10-12 students drawn from multiple sections of the undergraduate organic chemistry class at Madison, and I was flying by the seat of my pants in terms of what I knew of their curriculum. In some respects, I was Mrs. Smith during those sessions: relying on the science.

This experience provided me with a life-changing encounter. One of the graduate students whose project this was, Harry Behrman, was still collecting field data about the project and ended up observing my sessions. Over the course of that first year, Harry and I met for a few hours, most weeks, and I picked up an informal education in Education as a formal area of study. It was during these sessions that one of the most important Trostinspired messages collided with my prior and total ignorance about the field of education: identify a hard problem to work on, and do it creatively. At that moment, I could see the place and value for what I would, by the early 1990s, start calling "discipline-centered teaching and learning," an interdisciplinary area that emerges from the combination of one's understanding of a subject area with ideas from education. Really, I think Mrs. Smith invented it.

Most of the rest of this story, related to how this work turned into a tenured faculty line at the University of Michigan, is contained in Mary Taylor Huber's book, Balancing Acts: The Scholarship of Teaching and Learning in Academic Career (Huber, 2004).

\section{You have worked in the laboratory: could you mention some results you obtained?}

I love physical organic chemistry. You can design subtle, structurally based experiments; you can usually make the substrates you need; the experiments can be carried out quickly and on huge populations of self-equilibrating particles; and you get exact answers, at least in terms of the outcomes. Compare that with dealing with statistical inference, or with sitting under the earth waiting for a stray neutrino to come your way! I'm mostly kidding, here, because I am glad other people do all that stuff. But there is a lovely tangibility to tinkering with molecular structures, and then watching to see what they do, that I do not think we chemists do the best job in conveying. 
We studied one of the 1,3-dipolar cycloaddition (Huisgen) reactions notorious for giving low regioselectivities. Mesoionic münchnones, derived from the cyclodehydration reaction of secondary amido acids, give kinetically controlled cycloaddition reactions with acetylenic dipolarophiles to produce, after releasing carbon dioxide in a cycloreversion, pyrroles. The original synthesis of Atorvasatin (Lipitor) relies on one of these reactions.

In our studies, using isotopic labels, in one case, and using slight structural variation in the other, we were able to demonstrate that the regioselectivity in these reactions appeared to be more profoundly affected by non-covalent interactions, with some strong inferences about an unsymmetrical transition state structure, than the prevailing use of the Frontier Molecular Orbital model (Coppola et al., 1993).

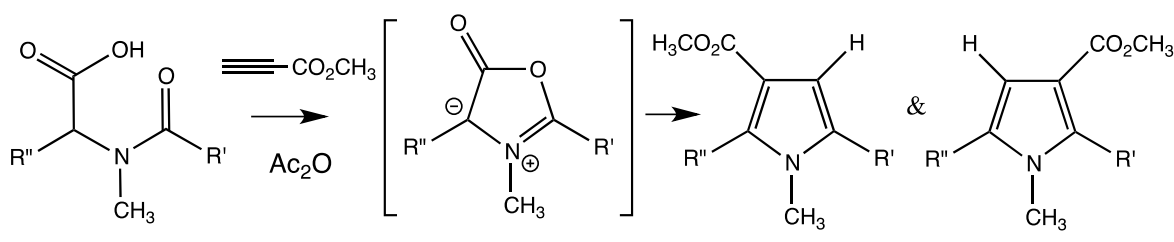

$\mathrm{R}^{\prime}={ }^{12} \mathrm{CH}_{3}, \mathrm{R}^{\prime \prime}={ }^{13} \mathrm{CH}_{3}$ ca. $50: 50$ $\mathrm{R}^{\prime}={ }^{13} \mathrm{CH}_{3}, \mathrm{R}^{\prime \prime}={ }^{12} \mathrm{CH}_{3}$ ca. $50: 50$

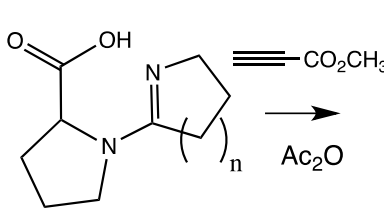

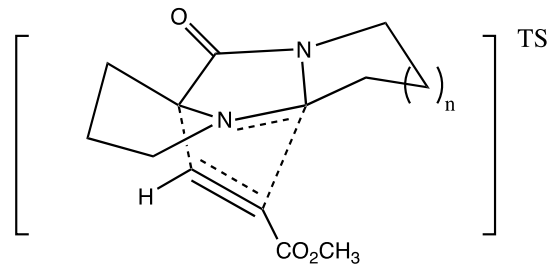<smiles>CC(=O)c1c(C(C)=O)c2n(c1CCCCN)CCC2</smiles>

normal cycloaddition with propiolate

$\begin{array}{ll}\mathrm{n}=3 & 89 \% \\ \mathrm{n}=2 & 35 \% \\ \mathrm{n}=1 & 11 \%\end{array}$

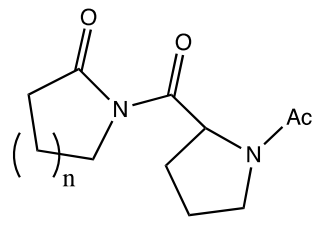

side reaction with $\mathrm{Ac}_{2} \mathrm{O}$

$0 \%$

$17 \%$

$33 \%$

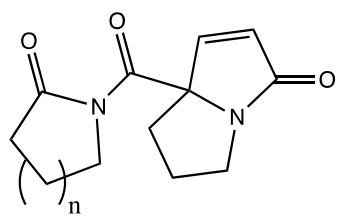

stepwise reaction with propiolate

$0 \%$

$0 \%$

$33 \%$

In 2009 you were awarded the prize "US National Professor of the Year" because of your "extraordinary dedication to undergraduate teaching" What qualities do you think are relevant for teachers?

If I may reflect on the question for just a moment: it is asked sincerely, but follows from a fundamentally flawed premise, namely, that by listing these qualities one can do something with them. Let's shift the frame of reference for a moment. If you were interviewing Martin Scorsese for his Oscar-winning directing, and you asked him what the qualities that are relevant for directors are, he might answer this way: learn how to tell a good story. I am tempted to answer the same way. 
I think that designing and implementing formal instruction is one of the most difficult and demanding performances that humans undertake. Few can do it extremely well and that many can do it in a serviceable way (NOW I am going to get into trouble). All of the typical performance-based professions share this character. Visual arts, dance, acting, music, and so on, all involve the deep personal experience of people with the world, and conveying how they see it through their particular instrument, in an attempt to get you (the viewer) to understand what it is about the world that they understand. They seek to evoke the understanding they have about the world, in others, which is not a bad way to think about what we mean by teaching.

Classroom or school-based instruction is, to me, a performance. Like a musician, we use "notes," but it is astounding how often the notes are confused with the performance in teaching. Think of the range of quality that occurs every day as however many individuals around the planet take up a given musical instrument to play a given set of notes. The virtuosos take their background, their experience, their view of the world, and try to express that understanding in a way, that evokes that understanding in those who are listening. The virtuosos may be playing the notes, but they are drawing everything of value from what is not written - call it "reading between the notes."

From person to person, the notes are exactly the same, but the combination of experience and ability results in an incredible diversity of performances. How many of these performances are horrible? How many are technically competent but evoke nothing? How many inspire understanding in a few? How many inspire everyone? In the performance arts, we make a keen distinction between technical competence and artistry. In the latter case, we see someone do something, and then we shake our heads and wonder "how the hell did he or she just do that?" This, to me, distinguishes the technically competent teachers from the outstanding ones.

As a teacher... as an effective teacher... you have to start with your deep understanding of the subject, about the nature of learning, about the audience, and you must not only write the symphony, you need to direct it, produce it, and then take the starring role. And without a doubt, just as when you are sitting one or one with a friend, you need to be able to read the most subtle clues in the reactions of your audience and, more often than not, re-write, re-direct, and re-produce your plan on the fly. Of all the different sorts of performance arts, I think that teaching most closely resembles improvisational jazz.

Some of the first students I ever had saw me doing this on-the-fly activity once in the middle of class, whereupon I erased the board and re-did what I was trying to say in a much more effective way than I had planned. One of them asked "Did you just figure that out?" and I replied "yes." "So I take it," the student remarked, "that one of the secrets of teaching is making something you learned only a moment ago look like something you have known all of your life?"

Moving away from this extended metaphor for a moment, the field of education calls this improvisational skill "Pedagogical Content Knowledge." More than just an understanding of your subject, and more than just an understanding of pedagogical strategies, PCK represents the strategic, in-the-moment choices that an effective teacher makes when thinking about how to evoke understanding in others. PCK involves the right diagnosis of what the challenge is in learning something, combined with the treatment (the right analogy, the right example, the right exercise) that exactly targets the problem that the learner is having. 
PCK is also at the heart of a truism: the skills of an excellent scientific researcher contribute to being an excellent science instructor. Again I get into trouble, because this is a hard pill for some to swallow. I do not think that all good researchers are good teachers, but if you take a PCK argument for what constitutes effective instruction, then one of the necessary conditions is that you have lots of authentic experience thinking about and doing science. When the time comes to face a bunch of students who have still not understood what they were trying to learn, effective teachers need to be able to plumb the depths of their own understanding in exactly the same way they make effective arguments in research. But this is not enough, because the effective instructor also has to repackage that knowledge and present the task, whatever it is, in a way that makes defensible sense for the intended audience. Knowing something is not the same as its effective explanation.

I've been at this for over 30 years now, and I still, on nearly a daily basis, find myself thinking in terms of what I know from doing science well, from the wealth of examples I know from the literature, and from the practices that characterize "the way science operates." At some point, less than a few weeks into any class I am teaching, the most recurring phrases I want to start to hear from my students are "what is the observation?" and "what are the data?"

\section{Even if students think differently, we believe that students are "best served by consistently being led to value discovery and true understanding."(Hoffmann \& Coppola, 1996, p. 394) How can we wake up the qualities that are in each student's mind?}

I like the way you have posed the question, so let me linger there for a moment because the subtlety is easy to miss. You did not ask "how can we place it there?" or "how can we teach it? But rather: how can we wake it up? Without stumbling into an extended nature/nurture argument, I think that the basic qualities for curiosity, creativity, imagination, analysis, and all the rest, are intrinsic to the human condition. What we can do for one another is to model the refinement and infinite expression of these qualities, and push to construct environments where others can learn from what we have learned.

I fully hope and expect that most of my students can exceed me in the expression of many things, but I also think I can exceed them in my ability to get it out of them... to leave them "a bit more awake" than when we first met. Honestly, I hope we all do this for one another, all the time. Teach me, because I love to learn. And because I love to learn, let me teach you something. The formal educational setting is only one place for this, but we hope that by coming together specifically for this purpose we can move more deliberately and efficiently than haphazardly.

As a teacher, I try very hard to construct this picture of myself as a learner who is merely sharing learning when I think about how to best inspire the development of these qualities in my students. I am convinced that $100 \%$ of my students can advance, and in doing so simply pick up on the aspects of these qualities that I am constantly illustrating and modeling. They might make greater, fewer, and different mistakes along the way. They might move at a slower or faster rate. But every student can make progress. I believe this and I tell them this, in my words and in my actions. If I do not believe this, they never will.

And certainly the converse is true. I have the same reaction every time I hear an instructor tell me, even before a course begins, all the reasons why the students will not 
be able to succeed: they do not have enough math skills, they do not speak English well enough, they scored low on some test, they are a bunch of grade-grubbing pre-meds who do not care about learning, and so on. "If you truly believe this," I say, "then this is exactly what the outcome will be."

\section{What are the best practices in the Teaching and Learning of Chemistry? What are the advantage of team learning you suggested? (Varma-Nelson \& Coppola, 2005)}

I think Heisenberg's famous idea about scientific uncertainty, that "method and object cannot be separated," (Heisenberg, 1958, p 29) is broadly applicable, so the question of best practices to teaching and learning must also ask: best practices for achieving what? The choice and success of a teaching method is linked to an instructor's objective. For example, I am less interested in whether hundreds of first-year university students recall the details of some organic chemistry mechanism and more interested in improving their ability to learn as well as in acquiring some enduring lessons, both which can be attached to learning the subject.

Enduring lessons include skepticism, the reliance on data and observation, the critical use of alternative hypotheses, comfort with ambiguity and the construction of the most defensible argument, Occam's Razor, the ability to convey a coherent argument, interpersonal negotiation skills, leadership, and so on, I do want students to retain a level of functional literacy about the subject matter so that they are comfortable with it when it comes up while they are watching Breaking Bad or listening critically when someone is trying to sell them a "chemical-free" product. And I certainly do not reduce the significance of the subject matter, by any stretch of the imagination, but I see the subject equally as serving an allegorical role. I cannot walk into class and say, "today you will learn about skepticism." Understanding skepticism is one of the morals of the story of science, while the facts and ideas of the discipline are the story I tell to achieve an understanding of the moral of the story: the enduring lessons.

The practices that strike me as the best ones are:

(1) Old school instruction: telling an evolving story, and learning how to do this well, including getting feedback, in rooms with hundreds of students. I have said often two things would improve the state of higher education overnight: eliminate Powerpoint ${ }^{\mathrm{TM}}$ and its ilk, and eliminate multiple choice testing. For all of the attention that the latest generation of classroom tricks has gotten, a simple fact is overlooked: an effective instructor can use a wet crayon on the sidewalk and do an excellent job. As a profession, I think we have lost an important connection to the true art of interactive and persuasive oral rhetoric (and good board work).

(2) Intellectual honesty to the subject matter. I want students to learn about the science of chemistry, not just learn how to do well on chemistry tests. I have zero tolerance for any other point of view. I know all the mantras: "But the students these days want this or that... but the students will give me bad ratings... but the students need to take the Medical College Admissions Test (MCAT)... but..." I simply do not care. Period. If I wanted to work at a test preparation company, I would do that, and I would do it well; but it would look quite different from what I do now. 
(3) Team based, or peer-to-peer, interactions. There is a lot of rediscovery and rebranding about team-based learning that has gone on, as people have scrambled to try and take ownership of an idea that is as old as humanity: telling the story of what you know to someone else, that is, teaching them, is a unique and indispensable part of learning. This lesson is critical to academic success because we invariably assess student understanding one way: we ask them to teach us, at least when the questions are open-ended, case studies, and/or based on data. What Elaine Coleman, more than anyone else I know, demonstrated empirically, years ago, is this: when you are cognitively aware of the future need to teach something to someone else, you will learn it better - the first time.

(4) Pedagogical coherence. As a community of organic chemists, for example, we really do not sit around and talk to one another about strategies for teaching organic chemistry. I am fortunate to be in a department, whose culture has grown in exactly this direction. Our multisection courses have evolved with a great deal of coherence in the strategies and bottom-line message about the subject as we teach it. This has resulted from years of actually talking with one another and seriously building up a way of approaching, thinking about, and teaching the subject. ${ }^{7}$ I have taught in a few other universities over the last couple of years, and I am certainly familiar with lots of departments. The advantages of a coherent program are that you actually improve the way you teach, you learn about the subject in ways you did not before, and the students do not end up with the sense that the different sections are competing with one another. Arguments that an individual is exercising academic freedom in teaching whatever way they want is just a misunderstanding of what academic freedom means.

\section{Education}

\section{Can you describe anecdotes that depict the effectiveness of your teaching strategies?}

I would say that it is having students achieve at levels that surprise them. One of the reasons I like teaching organic chemistry is that it is so easy to connect students with the actual work of a scientific discipline, from tying lessons together with stories about how knowledge is generated to the use of the primary literature for writing relatively open-ended exams that can be administered to 1500 students in an introductory class. This level of exposure to science is new to my students. As a scientist, I care about one overriding lesson: when students encounter new information, the first two questions they need to consider are "Do I believe this?" and "Does the evidence warrant the claims?"

Every year, then, since 1994, about 100-120 first-year students taking second semester organic chemistry transform a set of contemporary research articles into teaching materials for each other. We internally publish this 250-page book, and launch its companion web site, a multimedia feast, about 2 weeks before the final exam. This is peer-reviewed, studentgenerated work on which I base the questions for their final exam. My challenge to them is extreme: as good as the work is (and it is excellent), I base my exam questions only on whatever errors remain in their book. Inevitably, the students figure out that they (as a class) need to reserve a classroom to work with one another, as a cooperative community, in order to study for the final; after all, if they find something in their book or web site about which they have a question, they know who the authors are! 
On the first day of this class, my students are stunned because their laboratory syllabus after the mid-term break is literally blank. Once again, they use the chemical literature to devise simple, yet original, research proposals for what ought to constitute their work during the second half of the term. From about 30 team-written proposals, the class is responsible for reviewing and narrowing the field down to the best set of 4, at which point we order the necessary chemicals and have them ready for when the students return from Spring Break.

Whether it is the students who are taking these classes, or the ones who return to it and work as my collaborators - my teaching group - in order to be able to pull these things off, I think the effectiveness has two components. First, all of this crazy stuff gets done, and it is done well. You can push people pretty far beyond their expectations if you can figure out the right way to do it. Second, the important lessons seem to stick. One of my colleagues used a phrase, a number of years ago, to describe the character of the students who came out of these courses. He said that they had "naïve courage:" they did not know everything, but they thought they could do anything. They were not afraid to try new things, and if they did not know something they would automatically engage whatever resource they needed to learn from. He wished he had more graduate students like this.

First and last days of class are often memorable, and December 11, 2013 was a standout example of the latter. A few minutes before my 8:00 AM organic chemistry class, where the topics included the molecular basis of cockroach sex and how scientists clip the antennae of moths to electrodes in order to detect pheromones (don't ask), a tall student named Abdallah walked into my office. "May I read something to you?" he asked. "I wrote a poem for you last night and I want to read it to you." How can you say no to an offer like that?

\section{An Hour of Knowledge}

If Organic Chemistry was discovered by the Greek gods, It would have been make-believe.

Then Coppola lecturing every morning, Would be the equivalent of Winter time leaves.

Even then we'd fight for front row,

Everyone equipped with fishing rods.

And although it's too early for brain fluids to flow, We still ensure him with false nods.

His words are ice shards.

His breath is ten degrees beneath freeze,

Of liquid helium, yet we still come,

Under prepared wearing short sleeves.

Breathe, you will make it through the hour,

Keep your gaze focused,

Coppola's jokes are as funny as a flower

And his looks are like a punch line joke.

But that's only because they're the best part. 
Looking at his head,

Is as warm as a mother's heart.

Try and read his eyes,

You wouldn't know where to start.

He's fast at answering emails,

Quicker than a ninja's flying dart.

If you ever go shopping with him,

You better bring a big cart.

Auditorium with four hundred students,

Something is making this place go.

Protons and neutrons down below.

Electron orbitals shine their shadow.

Static forces are negligible,

It's the scenic exchange of knowledge,

Keeping the students inflow.

Coppola, you make chemistry glow,

You keep me up and fighting,

Staying toe to toe.

If this organic chem's an axiom,

Then man you've got an afro.

You wear Wisconsin shirts on Mondays,

To keep us all from falling asleep.

But you make all our days fun days.

So we don't consider counting sheep.

You can be shallow at times,

But that's to remind us that you're deep.

You drive through our heads like the new

Dodge Durango jeep.

So reap at our minds Coppola, reap!

Just clean the mess afterwards,

A quick mop and sweep.

As this semester comes to an end,

This hill is getting increasingly steep.

And this may sound awkward,

Professor, this may sound cheap.

I don't cry very often,

But my eyes are starting to seep.

I took an hour writing this out,

Not just for you to keep.

I also wrote this poem because

I'd hate for you to see me weep. 
At 9:00 AM, after that last class, after some applause, smiles and handshakes, Callie, one of the students who sat in the front row, handed me a densely inscribed card. She wrote, in part:

... When I first heard about classes, the "worst weed-out class," everyone said, was Orgo I. It was hard, brutal, and destroyed a 4.0. Leaving this class, I couldn't see a characterization farther from the truth. I am leaving Chem 210 with a deep understanding of the topics covered, an invigorated excitement for learning science, and - most importantly - a lot of really close relationships. Beyond the academic merit of the course, for me, the biggest gift has been the integrity that course has given me. First, integrity towards learning. Your dedication to your students and your discipline has always impressed me. I can't say how many of my peers have told me how much of an impact you have made on their 4 years at Michigan, and because of you, chemistry has gone from being my least to most favorite course. Second, I feel CHEM 210 (especially SSG) has given me a deeper sense of integrity towards the scientific disciplines in general. Orgo has not only taught me problem solving skills that have changed how I approach the world, but also an ethical paradigm with which to interact with it. More so than other courses, I feel the portable skills learned here have deeply influenced by approaches. Finally, I want to thank you for the incredible community CHEM 210 has given me. Without your emphasis on group collaboration, I wouldn't have met a group of amazing people. People see chemistry as such a hard science, but you have made it into a community, a home. You are changing lives every day - how many people can say that? - and are inspiring many others to do the same. Thank you for making my first freshman semester one I'll never forget. Namaste

\section{Can you involve students actively in a large class in a fixed-seat auditorium? If so, how?}

The short answer is yes, you can. Let me start with the underlying assumption that pervades education today, because it derives from the overwhelming shadow that accountability has cast over everything: the students need to be able to get answers to test problems correct. It is easy to measure this, and so it dominates. From personal response systems and small group work to flipped classrooms, the focus is quite squarely on reducing the DFW (D grade/ F grade/withdraw) rates and increasing overall test scores. Unfortunately, the effect is difficult to claim as anything other than creating better test-takers.

In my world, the college or university education experience is still about much more than GPA. I feel a keen obligation to keep the development of academic and moral intellect as the primary goals. I see an incredible difference between the focus on classroom and homework that dominates main features of the high school learning environment and the mastery of multiple and diverse resources that should characterize higher education. I want my students to learn organic chemistry, and all the appended gifts to their education that come with that, and not just how to do organic chemistry problems.

Frankly, I think the academic culture has lost this sense and replaced it with nonsense.

Now, do not get me wrong: subject matter mastery is the vehicle through which the lessons are delivered, and conceptual understanding is a key component. But so is helping to improve students' abilities to learn independently, particularly how to sort through the many strategic options for learning that are available to them and matching them up to 
themselves and to the learning task. This is called self-regulated learning. And there are appended lessons that come along with learning that are as difficult to teach as they are important, which are collectively relative to the traditional liberal arts outcomes. In science, in particular, things like skepticism, learning from failure, comfort with ambiguity and embracing uncertainty are things we can provide better than some other fields. Read again what Feynman said about Cargo Cult Science.

One of the nonsense assumptions of modern higher education is that the classroom in university occupies the same ecological niche that it does in high school, and so, in turn, do the teachers. I do not put all of my eggs into the basket of the classroom. It serves its purpose, but it is not the whole picture. And if a college or university instructor opines that their students just will not work out of class time, then that person has capitulated and gets exactly what is anticipated.

What I aim for with a class is an effective interactive performance, and I am using that term in the way I would if I was an actor, a musician, a dancer, or even a preacher. In an effective performance, you evoke an understanding through your expertise in the medium in a way that gets your audience to begin to appreciate what your years of experience, training, practice, and yes, your gift, brings to an interpretation and conveyance of feelings and ideas. Effective performance captivates, makes you think and want to remember even while you are listening, and you want - sometimes need - to reflect on that experience with others after the performance, to deconstruct it and construct your own understanding.

If you visit my classroom, then, you see a place (a) where I am concerned with the understanding of the subject, (b) where I am always looking for places to inject ideas related to learning the subject as well as the appended lessons to the subject, (c) where I have trained 300-400 students to be engaged in the performance to the point where when I pause in the middle of a sentence and expect them to have been listening, that they have been, and collectively, as a chorus, they do in fact fill in the words, (d) where I might pose small, fast questions 5-10 times in a minute, sometimes, and expect most of them to respond, collectively, as a chorus.

Choral response is difficult to impossible unless you can convince an audience to be listening and processing. And up in the front of the room, your ear can get tuned into some obvious differences: what does 400 people saying the same thing, quickly and with confidence, sounds like? What does 2, 3, or even 4 different answers sound like? What is the difference between a quarter second lag and a one second lag? What do the decibels tell me able their level of confidence? I can do this on the fly. I can then adjust immediately the direct in which I was headed, and then ask another question to see how that is going.

\section{What must be the role of the laboratory in chemical education? How it is possible "act as scientists and learn as a scientist learns"? (Gottfried et al., 2007, p 265)}

I have prided myself on being a good experimentalist, not only in the design of experiments but also in carrying them out. For a few years after I left graduate school, people who needed to reference my notebooks, for example, took the time to compliment me on my work. All of which is to say that I think the experimental aspects of science are important. Let me be clear: if you know the outcome, it is not an experiment. Learning how to translate this into undergraduate laboratories is extremely difficult, particularly on 
a large scale. And like high school, the training and experience of the in-class instructor is the biggest variable. The less well trained or experienced a person is, the less capable they are at truly designing and implementing effective instruction, and you end up with exercises rather than experiments.

Over the years, I have been inspired by the idea that even a small unknown is still an unknown, and so experiments can be done in classroom settings. I want students to have a hand in developing their skills, in being able to contribute to design, and to have to rely on the interpretation and evaluation of data. I do not think that every student needs to maximize the yield of benzoic acid as derived from phenyl Grignard and dry ice. But we have figured out a way to make this an interesting experiment. As it turns out, there are byproducts in this reaction that have been systematically excluded through the classical experimental procedure. One of these is biphenyl. One way to get a couple of good years of experimentation out of the benzoic acid exercise is to ask the question: how will different experimental conditions effect the distribution of products? A hypothesis can be created and tested. The results are what they are.

One design that I like is to find some simple organic methodology that has been reported on 10-15 substrates, and which, according to the literature, can be realistically accomplished in a standard undergraduate laboratory period. Then I will devote three weeks to this. During the first week, I will ask students to practice developing their manipulative skills be reproducing a literature example. Next, I will buy some of the related by untested substrates, and then ask them to see if the procedure works on that substrate. And finally, whatever that result, I want the students to swap substrates and see if the result can be replicated.

The rise of instructional technology can deeply modify higher education. (Pienta, 2013) Will teachers be replaced by computers?

This refrain has been sung time after time. The rise of books, postal service, radio, television, and the internet have all heralded the end of education as we know it. But as long as we hold the highest values possible as the outcome from education, then this is not related to the medium, it is related to the message. Tools and the use of tools always depend on the skill and talent of the human mind and body. If you give me a Stradivarius violin, I will not play it any better than I can play a tin can outfitted with a stick and two strings. As your skills to learn improve, it becomes easier and easier to learn on your own, through a variety of media. I think it's a mistake to confuse the direction of the arrow, there.

\section{Motivation and cognition are important in the learning of chemistry. What role does motivation play?}

As far as I know, motivation is important for learning everything, so I do not think it is possible to find anything special about chemistry in there. Motivation is a combination of extrinsic and intrinsic factors that tie together deeply the twin features of goals and effort. Extrinsic motivation derives from external reward. The part of the work you do for your salary. The things you do for praise. The work students do for grades, letters of recommendation, and so on. There is a tendency by some purists to discount the value of 
extrinsic motivation in favor of intrinsic motivation. I do not see it that way; I definitely favor a combined and aligned pairing of doing something for its internal, intrinsic value, and then tying the external reward structure to having done that.

Intrinsic motivation has gotten the most attention because of Mihaly Csikszentmihalyi and his notion of "flow." The original Optimal Experience book is excellent (Optimal Experience: Psychological studies of flow in consciousness). If you imagine a coordinate system where "effort" is along x-axis and "challenge or skill level" is along the y-axis, then Csikszentmihalyi, in his studies of people who achieve at high levels in areas of little extrinsic reward (mountain climbing, for instance) all described a diagonal balance between effort and challenge. That is, as you expend effort (strategic thinking, practice), you want to see it pay off in getting better at whatever it is you are trying to do. But if lots of effort results in small or no gains (slope $=0$, in the limit), then there is no motivation to continue (no improvement). If only a little effort is needed to get great (slope = infinity, in the limit) then there is no need to expend more effort thinking about it. What Csikszentmihalyi found was that people persisted when the ratcheting of skill level and effort was well matched. The next moderate level of challenge would motive the effort, and the effort was rewarded by increased skill. He called staying moving inside this zone of continuous improvement as being in the flow, a term originally used by some of his subjects. If you fall outside the flow, because effort does not pay off, or the challenge increases rapidly, your intrinsic motivation falls off.

For educators, these ideas align strongly with Vygotsky's notion of identifying the Zone of Proximal Development for students: those challenges that are not just the same as what has been done before, but which builds on it (prior knowledge) and is also not so far outside their reach based on some rational effort. Providing guidance to students as they move into this challenging territory based on our own expertise (scaffolding) is reasonable.

\section{You talk about communication of knowledge, connections, stories, improvisation: what is the recipe that make your lectures memorable?}

I think there is a list of ingredients, but even then, you cannot infer the recipe from the ingredients, and if you cannot describe what I think is an internal, tacit process for how things are combined when they totally depend on the context and the audience. I think some critical ingredients that work for me are as follows.

(1) My understanding of the subject matter. This is the well from which good teaching flows. It is a necessary but insufficient feature of teaching excellence. I see there is an entire question on this later, so I will defer to some of those others, here.

(2) Performance, as I have described it, which is the ability to take meaning from information and convey it in a way that allows others to take the meaning without necessarily having had to experience it. If you have ever had an emotional reaction to the work of an actor, or a musician, because they conveyed, through their performance of a script (notes) a sensation that caused it to be evoked in you, then you begin to see what I mean. If you think you can go into the classroom and do what I do because you ask me for me notes, then you do not understand, because you have no idea how I play them! The performance is how I enact what I understand based on the notes. 
Performance, as I have described it is the key to an effective act of persuasive oral rhetoric. Although we know that an audience can only put up with 15-20 minutes of droning before they need a break, we also know that people can be attentive to movies, books, games, theater, concerts, etc., and sometimes under less than ideal conditions, but sometimes with as much (I would argue) that is being learned or demanded of them, for hours! This contrast does not support strongly the interpretation that "the lecture format" is intrinsically bad, but rather that the level of performance needs to be high enough, and that the narrative flow (sic) needs to be coherent enough, so that you are in the zone of your audience. David Feldon points this lesson out quite well when he says (paraphrasing): do not confuse the bad use of a method with the use of a bad method.

(3) Interactive improvisation. We do this all the time when we talk with people. I say something, and I seek out, elicit, or pay attention to the clues that let me know if you have understood what I am saying, that is, if you learned it. If not, then I back up, ask questions, let you reflect back to me what you heard, and we go back and forth to construct a common understanding. The more what I am trying to tell you sits outside of your experience, the more it falls to me to try and take your prior knowledge and find the entry points for you to get my meaning. Lateral thinking and analogical reasoning play large role in this.

(4) The "gotcha moment" of good storytelling. Good stories have a few recurring features. Sometimes, a person looks at something you have seen all of your life, and brings a kind of sideways perspective that you never thought of before. George Carlin was good at this. Sometimes, you know a person is laying all the items out in front of you, and no matter how hard you try, you cannot see the interesting or surprising denouement that will bring all the information together in one fell swoop. Paul Harvey was a master of this, as was Isaac Asimov. I think this happens in good teaching all the time, as the apparently diverse and disparate information congeals under a single conceptual understanding - we call it The Big Picture. And I am a fan of Big Picture instruction that is, not keeping the punch line a secret, but moving back and forth between the big picture and the puzzle pieces that make it up. That moment of synthesis needs to be within the zone of proximal development of the students however, or the big reveal will just be a big dud.

(5) Teaching by example, not just teaching the examples. In September 2009, Ben, a student from the first class I ever taught as a professor, back in 1982, died in a freak accident. He was a beloved country doctor in Wisconsin, and his best buddy (Greg, also a physician) wrote to me. I had not heard from either of them since they graduated, 25 years earlier.

Greg wrote: "Ben and I always saw ourselves as teaching our patients according to your example. The memory that just stuck with us was you sitting on the edge of your desk before starting a lecture. I don't know if you did that on purpose, but I have to tell you, that casual act helped disarm a lot of the intimidation and fear Ben and I had about organic chemistry. It was a brilliant teaching move. We used our own version of this all the time." At its best, education blends multiple lessons that include the subject matter along with every choice, large and small, that a teacher makes. 


\section{Scholarship of Teaching}

Does a university teacher's understanding of the subject matter they are teaching have anything to do with the scholarship of teaching?

I am a strong advocate on this point: I think that subject matter understanding has something to do with everything when it comes to teaching and learning. I do think it is necessary and not sufficient, because there are other factors. My expertise is my foundational strength in teaching science. The emergence of discipline-centered teaching and learning at the post-secondary level has made the last 30 years pretty interesting. Joe Krajcik and I covered what I think are some of the salient features of what makes the discipline such a central feature (Coppola \& Krajcik, 2013).

As an organic chemist who continued to enjoy doing organic chemistry with my undergraduate research students, my understanding of the subject matter is inextricably tied to my understanding of how the science is done. My argument is that truly discipline-centered work means that the factual subject matter cannot be pulled apart from the experimental methods, the epistemological orientation, or the collection of feelings and behaviors that all go into carrying out science.

One of the reasons I love teaching organic chemistry is that I think it occupies a special place in science instruction. At least in the United States, it is the first time that students are taking a course that is an actual area of science, and one that is most likely taught by a practitioner of that particular subject area. Think about it. Until organic chemistry, it's all been General Chemistry, General Biology, and so on. As students move on, it gets more and more likely that their professors have research expertise in the area being taught, and this gives (I would say) at least the potential for a huge difference compared with introductory classes. I am convinced that this deep, inextricable connection, and my awareness of it, makes me a good organic chemistry teacher but would make me, at best, a mediocre physical chemistry teacher.

I think this same disciplinary understanding means that I can design and implement instruction in ways that non-organic chemists cannot do, and I think I can design, carry out, and interpret the results from experiments in organic chemistry education research that a person who is not an organic chemist cannot, either.

You observed that "understanding that students are learning better is a more complicated problem than determining percent yield and purity" (Coppola, 2007, p. 1909). Instead of blaming high school teachers, how can the universities help them in enhance their professionalism?

Although it sounds like I am blaming the high school teachers, I am really being critical of the system that trains them, and the much larger academic and societal context in which all of that sits. All of my best ideas are simple and unworkable (Coppola \& Zhao, 2012): (a) give all teachers an across the board raise by making school teaching a tax-free profession; (b) make it a law, through the national accreditation process, that universities must demonstrate convincing and substantial collaboration between disciplinary units and the schools of education on the question of teacher training and continuing education. 
In my few associations with the teacher education community, I am struck by a deep tradition of conservative, traditional strategies that are clearly not doing the job. I was dumbfounded, years ago, when a publisher told me to assume that $75 \%$ all people standing in front of a chemistry classroom in the United States have one year or less of college chemistry. If I can think of those two crazy ideas, above, then why do we not at least hear about the top 100 crazy-but-big ideas about how to make systemic change, rather than the vested interests of people who are trying to sell their pet programs?

I think models for sustained relationships between universities and schools are a possible key strategy. For a few years, my former U-M colleague, Joe Krajcik, and I, implemented an idea we called FUTURE (Foundations for Undergraduate Teaching: Uniting Research and Education). We had a little money to work with, and we went out into the Southeast Michigan community and asked teachers to be the Principal Investigators in their own classrooms. We did not go out with a curriculum, nor did we go out with a pre-set agenda. We went out with a question: is there something you have always wanted to do in your classroom that you have not been able to do, for whatever reason? We are not interested in wholesale curriculum reform, we are interested in a lesson, a lab, anything that answers the question for one teacher in one classroom. We then offered resources, the most important one was that we would set up a match-making between them and two or three undeclared first-year undergraduate students who were enrolled in science classes and who would be that teacher's team.

The teachers came to campus and described what they wanted to do on some poster boards and easels. These were often modestly described ideas: a lab that uses probeware, a lesson in green chemistry, something to do with oxidation reactions. The teachers put up their schedules, and undergraduates were invited to the session to see what was intriguing to them, and whether their schedules might match up.

For the first half of the term, the 2- to 3-student team was the R\&D group for the teacher, who was the project director. With a few on-site classroom visits and some email conversations, the students and the teacher developed lesson plans and materials for a 3-5 day intervention derived from the teacher's interest. On campus, we provided consultant graduate students from education and from science, and access to laboratory resources. We bought what we needed (like the probes) with the idea of creating a repository of tested lessons and materials, over time. We provided modest stipends to the students and the teachers for participating. During the second half of the term, a time was arranged for the students to join the teachers in their classrooms and co-teach these lessons that they developed, as a team.

Within just a few semesters, we had hundreds of students working with teachers, and began to create a sustained relationship between the university and a set of local schools, particularly some in highly underserved areas. Every teacher who started with us would return the next term to further refine the idea or pick up a new one. 
Because fewer students are attracted by science, maybe we as teachers scare them. What advice could you give about a suitable curriculum and a proper approach to teach it?

Curriculum matters, but not as much as we give it credit for. I think there are principles that can guide the implementation of many different ideas. I also think a talented teacher can make do with chalk, a wet sidewalk, and a couple of rocks, while the concept of "teacherproof teaching materials" makes my skin crawl.

I do think it is time to drag the introduction to chemistry into the late twentieth century. There are ideas that need to be buried, such as any formal notion of definite and multiple proportions, which predate the modern conception of bonding and molecular structure. To wit: any program that writes " $\mathrm{H}_{2} \mathrm{O}$ " prior to its discussion of definite and multiple proportions is using the result, already. Molecules happen. The end. Exactly what opportunities to actually learn some chemistry are being lost in order to satisfy late $18^{\text {th }}$ century science?

From my perspective, I would like students entering college with a working understanding of three principles (meaning that they have enough of an understanding to explain and illustrate and defend the points).

(1) In a chemical reaction, atoms are conserved.

(2) Except for unusual situations, chemical reactions are not explosions, that is, they are not described by the disassembly and re-assembly of atoms.

(3) Simple valence considerations are all that is needed for dealing with the main group elements.

Then I would pick a system to develop that could be kept for the entire year, building in complexity and conceptual understanding. There are many candidates, but I would love to see a high school chemistry program built around understanding the structure and function of hemoglobin. Think about that for a moment. Take a complex description of the structure and function of hemoglobin and start working backwards to decide what you need to know in order to understand it, and the order in which you would build the story. The more you think about it, the more obvious it gets.

\section{How can research in chemical education be more effectively transformed into improved teaching and learning?}

First, I think we have to be careful. Education experiments are not chemistry experiments, and every result is conditional on such a large number of contextual features that I am comfortable with thinking that the principle concepts that drive these experiments should be carefully considered to see if there is a local application or adaptation that works.

I recall the first few years of our new undergraduate curriculum, when we were giving talks about the program. I had just completed giving a seminar at my graduate alma mater, the University of Wisconsin-Madison, and the first question came from Hans Reich. You were a student here at UW, he said, and you know us. How much of this do you think we could do here?

My answer today is exactly the same as it was 20 years ago: all of it, or none of it, it just depends what you think could work in your context. The principled concept in our program is not the sequence of classes or those four questions I mentioned. The principled 
concept is to look around, take stock of your strengths and weaknesses, and design something that plays off the former while minimizing the effects of the latter. To this day, I honestly believe that this is best answer, and one that is substantially better than shopping around for what other people are doing, or trying to sell you.

Let me make this clear: it does not mean re-inventing the wheel, you should always work in an informed way. This has been true for us. As the department has changed, the program has changed. I hope we represent a model for continuous improvement. But this is true: the program has changed as we have changed. Some features remain; some evolve; some disappear; some are added. The thing we have in place - and while it is not perfect, it is rather unique - is an institutionalized mechanism to support continuous change within the department.

\section{Globalization of Chemical Education}

You have been the very first American professor to teach organic chemistry in a Chinese university and you know some Asian academic cultures. What are the strengths of the two systems? How Asian countries do to make chemistry teaching relevant?

The basic chemistry knowledge of a student in China who took the chemistry track in high school is impressive, in terms of their exposure to a sheer number of facts and ideas. Their teachers are trained at the Normal Universities, and have usually carried out advanced research, sometimes at the $\mathrm{MS}$ or $\mathrm{PhD}$ level, in addition to their teacher training. These are bona fide chemistry departments where training in research and teaching is integrated.

Now, remember I am reporting first-hand experience with $\mathrm{N}=1$ (one time, one person, one department), and I have no generalized knowledge about this topic (although I am working on ways to get that). That said, the thing that I thought was missing in my Chinese students was the ability to make rapid moves in analogical reasoning, being able to move fluidly back and forth with inductive and deductive reasoning. My students in China were capable of doing this, but they have never seen it done, and they had no practice. With coaching, during class, they were completely capable. In fact, I thought they were quite funny sometimes, because they did have so much of the prerequisite factual information, that every now and then the ramifications of what I was saying were unifying huge blocks of their previously disconnected prior knowledge could cause them to gasp or burst into spontaneous conversation.

So, the strength of their system is the ability to produce students with a greater degree of factual knowledge and laboratory experience; and this is our weakness. At least for now, however, the strength of our college and university experience, and this greater degree of experience with more fluid, lateral thinking, I think enables students in the US to make up a great deal of this difference. 


\section{References}

Coppola, B. P. (1998). Progress in Practice: Three plenaries. I. Richard N. Zare, enhance, enable, and elucidate. The Chemical Educator, 3 (3), s00897980215a.

Coppola, B. P. (2001). Full human presence. In A. G. Reinarz, \& E. R. White (Eds.), Beyond teaching to mentoring. New directions in teaching and learning no. 83 (pp. 57-73). San Francisco: Jossey-Bass.

Coppola, B. P. (2002). Strength in numbers. Making the large lecture course work for you. In C. A. Stanley, \& M. E. Porter (Eds.), Engaging large classes. Strategies and techniques for college faculty (pp. 257-268). Bolton, MA: Anker.

Coppola, B. P. (2007). The most beautiful theories. Journal of Chemical Education, 84 (12), 19021911.

Coppola, B. P. (2013). The distinctiveness of a higher education. Journal Chemical Education, 90 (8), 955-956.

Coppola, B. P., Ege, S. N., \& Lawton, R. G. (1997). The university of Michigan undergraduate chemistry curriculum. 2. Instructional strategies and assessment. Journal Chemical Education, 74 (1), 84-94.

Coppola, B. P., Hovick, J. W., \& Daniels, D. S. (1994). I scream, you scream ... A new twist on the liquid nitrogen demonstrations. Journal of Chemical Education, 71 (12), 1080.

Coppola, B. P., Krajcik, J. S. (2013). Discipline-centered postsecondary education research: Understanding university level science learning. Journal of Research in Science Teaching, 50 (6), 627-638.

Coppola, B. P., \& Lawton, R. G. (1995). Who has the same substance that I have? A blueprint for collaborative learning activities. Journal of Chemical Education, 72 (12), 1120-1122.

Coppola, B. P., Noe, M. C., Abdon, R. L. II, Konsler, R. G. (1993). A new observation of limiting case 1,3-dipolar cycloaddition. Evidence for a highly unsymmetrical transition state structure with the reactions of mesoionic compounds. Journal of Organic Chemistry, 58 (26), 7324-7327.

Coppola, B. P., Noe, M. C., \& Hong, S. S.-K. (1997). Regiocontrol in the 1,3-dipolar cycioaddition reactions of mesoionic compounds with acetylenic dipolarophiles. Tetrahedron Letters, 38 (41), 7159-7162.

Coppola, B. P., \& Zhao, Y. (2012). U.S. education in Chinese lock step? Bad move. The Chronicle of Higher Education, Retrieved from http://chronicle.com/article/US-Education-inChinese/130669/ (February 15, 2017).

Ege, S. N., Coppola, B. P., \& Lawton, R. G. (1997). The university of Michigan undergraduate chemistry curriculum. 1. Philosophy, curriculum, and the nature of change. Journal Chemical Education, 74 (1), 74-83.

Gottfried, A. C., Sweeder, R. D., Bartolin, J. M., Hessler, J. A., Reynolds, B. P., Stewart, I. C., Coppola, B. P., \& Banaszak Holl, M. M. (2007). Design and implementation of a studio-based general chemistry course at the University of Michigan. Journal of Chemical Education, 84 (2), 265-270.

Heisenberg, W. (1958). The physicist's conception of nature. New York: Harcourt, Brace \& Co.

Hoffmann, R., \& Coppola, B. P. (1996). Some heretical thoughts on what our students are telling us. Journal of College Science Teaching, 25, 390-394.

Hoffmann, R., Schleyer, P. v. R., \& Schaefer III, H. F. (2008). Predicting molecules-more realism, please! Angewandte Chemie International Edition, 47 (38), 7164-7167.

Huber, M. T. (2004). Balancing acts: The scholarship of teaching and learning in academic careers. Washington, DC: American Association for Higher Education and the Carnegie Foundation for the Advancement of Teaching.

Jones, P. R., \& Coppola, B. P. (1978). Animated alchemy. Journal of Chemical Education, 55 (1), 6. 
Pienta, N. J. (2013). Online courses in chemistry: Salvation or downfall? Journal Chemical Education, 90 (3), 271-272.

Varma-Nelson, P., \& Coppola, B. P. (2005). Team learning. In N. J. Pienta, M. M. Cooper, \& T. J. Greenbowe (Eds.), Chemists' guide to effective teaching (pp. 155-169). Saddle River, NJ: Pearson Education, Prentice Hall.

Zusho, A., Pintrich, P. R., \& Coppola, B. P. (2003). Skill and will: The role of motivation and cognition in the learning of chemistry. International Journal of Science Education, 25 (9), 1081-1094.

Received 15 March 2017; accepted 25 April 2017

\section{\begin{tabular}{ll}
\hline & $\quad$ \\
& Liberato Cardellini \\
\end{tabular}}

PhD., Associate Professor, Marche Polytechnic University, Department SIMAU, Via Brecce Bianche, 12, 60131 Ancona, Italy.

E-mail:1.cardellini@univpm.it

Website: www.univpm.it/liberato.cardellini 